\title{
THE PROMISES OF EDUCATIONAL TECHNOLOGY: A REASSESSMENT
}

\author{
DONALD P. ELY and TJEERD PLOMP
}

\begin{abstract}
The claims made for educational technology have not always been realized. Many programmes in education based on media and technology have produced useful documentation and supportive research; others have failed. The current, comprehensive definition of educational technology is a helpful key to understanding how a problem-solving orientation is necessary to approach teaching/learning designs. The process of educational technology begins with an analysis of the problem, rather than with the medium as a solution. Examples of appropriate applications come from open universities and primary schools where distance, time, insufficient personnel, and inadequate facilities have led to a search for alternative means for teaching and learning. Less successful programmes tended to have confused goals and an emphasis on one medium. They also lacked: support services, staff training, quality software and a system focus. The threads which run through the more successful programmes are described. The lessons learned from fifty years of media and technology development in education and training are discussed with an eye toward the future. It is clear that educational technology as a problem-solving process will lead the field into the twenty-first century.
\end{abstract}

Zusammenfassung - Die an Bildungstechnologien gestellten Ansprüche werden nicht immer erreicht. Viele auf Medien und Technologien aufbauende Bildungsprogramme haben nützliche Dokumentation und die Bildungstechnologie unterstützende Forschung erstellt; andere blieben erfolglos. Die derzeitige, umfassende Definition der Bildungstechnologien ist ein hilfreicher Schlüssel zum Verständnis dessen, wie notwendig eine problemlösende Orientierung ist, um Lehr- und Lernentwürfe in die Wege zu leiten. Der bildungstechnologische Prozeß setzt ein mit einer Analyse des Problems anstatt mit dem Medium als Lösung. Beispiele angemessener Anwendungsformen kommen aus den 'open universities' und Primarschulen, wo Entfernung, Zeit, Personalmangel und unzureichende Einrichtungen zur Suche nach alternativen Lern- und Lehrmitteln geführt haben. Weniger erfolgreiche Programme neigten dazu, daß die Ziele unklar definiert waren und die Betonung auf einem einzigen Medium lag. Es mangelte ihnen auch an unterstützenden Dienstleistungen, Personalausbildung, Qualitätssoftware und einem mittelpunktbezogenen System. Die Leitfäden erfolgreicher Programme werden erläutert. Das in 50 Jahre langer Medien- und Technologieentwicklung in Erzichung und Ausbildung Erlernte wird im Hinblick auf die Zukunft besprochen. Es besteht Klarheit darüber, daß die Bildungstechnologie als Problemlösungsprozeß dieses Gebiet in das 21. Jahrhundert führen wird. 
Résumé - Les revendications faites au nom des technologies éducatives n'ont pas toujours été réalisées. De nombreux programmes d'éducation basés sur les media et les technologies ont fourni une documentation utile et une recherche étayée. D'autres ont échoué. La définition globale actuelle des technologies éducatives est une aide précieuse pour comprendre la manière dont une démarche fondée sur la recherche de solutions aux problèmes est nécessaire dans l'approche des projets d'enseignement-apprentissage. Le développement des technologies éducatives part de l'analyse du problème plutôt que du moyen en tant que solution. Les exemples d'applications appropriées nous sont fournis par les centres de téléenseignement universitaires et les écoles primaires où l'éloignement, le temps disponible, l'insuffisance numérique du personnel ainsi que l'inadéquation des équipements ont conduit à la recherche d'autres moyens d'enseignement et d'apprentissage. Les programmes qui ont obtenu moins de succès avaient une propension à confondre les objectives et à placer un accent sur un seul moyen. Les supports, la formation des enseignants, les logiciels de qualité et un système au point faisaient défaut. Les grandes lignes des programmes qui ont été couronnés de succès sont décrites. Les leçons tirées des cinquante années de développement des media et des technologies en matière d'éducation et de formation sont examinées avec un regard porté vers le futur. Il apparaît évident que les technologies éducatives perçues comme méthodes de 'solution d'un problème feront entrer l'éducation dans le vingt-et-unième siècle.

Over the past fifty years educational technology has evolved from its early emphasis on the protection and use of the media and instruments of communication to its current concern with the systematic approach to solving educational problems based on theories of learning and instruction. This time has been marked by the arrival of new technological developments, each one of which has been heralded as a major breakthrough with a potential for revolutionizing education. The historians of educational technology (Saettler, 1968; Cuban, 1985) have documented the movement from radio, motion pictures, and slides to television, programmed instruction and computers. In each case the new technology has been touted as a replacement for textbooks, an extension of the classroom to the world, or a complement for some of the instructional functions. However, the present authors, in surveying the current scene, do not see evidence of significant, revolutionary use of the various communication technologies. Their isolated use in different areas of the world can be observed, but there are no major educational innovations or movements which promise to bring about the changes which are so desperately needed (Faure et al., 1982; Botkin et al., 1979).

What has happened to educational technology during the past fifty years? Is there any residue from the myriad efforts to introduce the concepts of media and technology into educational systems in many parts of the world? Are there lessons we can learn from these efforts which might enable us to consider more fully the merits of future technological developments?

The purpose of this article is to present an interpretation of educational 
technology, including its roots, its definition, its areas of application, and its development. This background survey is followed by a discussion of the educational problems which could be addressed by educational technology. There then follow a catalogue of applications of educational technology which have attempted to resolve some of the problems, and an analysis of the 'successes' and 'failures' of the programmes described. The common threads that emerge from these analyses are picked out, and finally a listing is given of what has been learned in the process.

\section{What is Meant by Educational Technology?}

When the term 'educational technology' is used, it often carries the media connotation which focuses on equipment and materials, i.e., the delivery systems. In fact, in the United States, the Presidential Commission on Instructional Technology (Tickton, 1970) gave two definitions of the field and the first emphasized the hardware and software:

... the media born of the communications revolution which can be used for instructional purposes alongside the teacher, textbook and blackboard ... the pieces that make up instructional technology: television, films, overhead projectors, computers and the other items of 'hardware' and 'software'. (p. 5)

But the report goes on to say that there is an emerging second definition which might be more important in the future:

A systematic way of designing, carrying out, and evaluating the total process of learning and teaching in terms of specific objectives, based on research in human learning and communication and employing a combination of human and nonhuman resources to bring about more effective instruction. (p. 5)

This process definition is much more amenable to emerging concepts in the field and is compatible with the first and second definitions of Lumsdaine (1964) and Romiszowski (1981). Davies (1971) proposes a third interpretation which combines the hardware and software aspects of the two definitions and builds a bridge between educational theory and practice yielding 'a science and an art of teaching with a technology of its very own' (p. 15). Romiszowski (1981) speaks of a product versus a process approach of educational technology, and Davies (1973) of a hardware versus software approach. Historically, both approaches had their supporters. Those supporting the product definition came mainly from an audiovisual orientation and from media producers. The early advocates of the process approach could be found mainly in the circles of psychologists and training developers. It can be concluded from the early literature of the field that both groups operated rather independently from each other. 
The definition of the field may be used in a variety of ways. For some, it is useful to help describe a profession; for others, it is a description of what practitioners do; and for still others, it helps to limit the scope of their activities so that individuals know who is 'in' and who is 'out' (Ely, 1983). Educational technology is an elusive field because it draws on such diverse roots and because it finds the bulk of its activities in many applied areas. Primary contributory fields include psychology, communications, management, and engineering (Stakenas and Kaufman, 1981). In its applications, educational technology can be viewed as technology when referring to the methodology of its problem-solving aspects; it can be viewed as media when aids to learning are required and instructional surrogates are appropriate; and it can mean technique when it is employed as a teaching/learning method as in a simulation/game or in computer-assisted learning. It may be a change paradigm in the classroom or school building at the micro-level or an entire school system at the macro-level. Distinctions are often made in describing educational technology when it is used for training purposes and when it is used for the attainment of educational goals (Ely, 1985). Heinich (1984) insists that

the root of instructional technology is technology itself. Instructional technology as a field of study is better considered as a subset of technology in general than as a subset of Education. (p. 67)

His meaning of technology is rooted in the problem-solving mode.

It may sound pretentious to say that educational technology is all of these but, in fact, it is. All the factors mentioned above are not simultaneously operational but most of the aspects of the field do come into play at one time or another in a systematic fashion if a solution is being sought following a technological approach.

\section{Conceptual Evolution of Educational Technology}

In the sixties it was realized that real improvement of education could not be attained by focusing on independent parts of the system. Instructional methods or modes of presentation could not be replaced by machines and/or methods in vogue without real changes in the configuration of the educational process. Curricular materials (including all types of media), teaching strategies and teaching philosophy are so interrelated and interconnected that one cannot change one without considering changes in the others (Fullan, 1982). Inspired by developments in other disciplines, like engineering and management science, a holistic approach gradually developed, i.e., 
a problem cannot be isolated from its context or environment, but has to be analyzed in that context or environment. It is not self-evident that every problem in education or training should be solved by using media or even by using new instructional strategies. Implicit in this holistic approach is the need to be alert to the many factors which determine a problem situation and to those which can play a role when searching for a solution. This new development has resulted in a broader meaning of educational technology to which the Association for Educational Communications and Technology (AECT) has given a comprehensive description/definition:

Educational technology is a complex, integrated process involving people, procedures, ideas, devices and organization, for analyzing problems and devising, implementing, evaluating and managing solutions to those problems, involved in all aspects of human learning. (AECT, 1977)

Several other authors have associated themselves with the broader meaning of educational technology. Davies (1973) and Romiszowski (1981) characterize educational technology as a method for solving educational problems. This method is discussed by many authors, often for specific classes of problems (see Gerlach and Ely, 1981; Gagné and Briggs, 1977; Davies, 1973; Romiszowski, 1981; Dick and Carey, 1983; Plomp, 1985; Diamond, 1985). These authors all speak of a systematic or a systems approach consisting of the following general phases: (1) Analysis and definition of the problem, (2) Selection or design of a solution (from a set of alternatives), (3) Development of the solution, (4) Testing, evaluating and revising, (5) Implementing and controlling. This process is not a linear but an iterative one in which creativity and a heuristic (instead of algorithmic) approach are important features. In such a technological approach one strives for acceptable and attainable solutions, and not always for the best one (from a scientific point of view). The limitations imposed by the problem context will ultimately be more influential on the choice of the best alternative than on scientific arguments. Although no guarantee can be given that the best solution will be achieved, the systems approach to educational problem solving will result in an optimal chance of arriving at an acceptable solution.

The most important methodological aspects of an educational technology approach can be divided into three categories:

a) Educational technology as systems

Using concepts and approaches of systems theory and operations research in the analysis phase, the problem can be handled by defining the problem space as a system with boundaries, within which related subsystems can be defined. Complex problems can be unravelled to reveal wellordered partial problems with enough known properties to make an acceptable solution possible. 
b) Educational technology as methods and techniques

Many techniques, most of which are not specific to educational technology, can be used in the analysis, design, development and evaluation phases. The specificity of these techniques lies in their order within the technological cycle. This cycle can be considered as the methodological basis for the design process. A typical characteristic of educational technology is that techniques for design decisions are considered to be a vital part of the process.

c) Educational technology project organization

A technological approach makes special demands on the organization of projects. This is partly due to the fact that the problem analysis will result in an overview of knowledge and skills needed for finding a solution. Many problems need expertise from a variety of disciplines. 'Management of expertise' is the key phrase: the classification of a problem with the right expertise at the right time. Continuing attention to the implementation of the solution makes demands on the project organization. Planning has to be considered as one characteristic of a technological approach. The project organization is directed at achieving an optimal solution within the existing constraints such as budget, personnel and time.

Educational problems may occur at all levels. At the macro-level there are the national problems concerning the educational needs of the society as a whole: policy, structure of the system, minimal facilities needed for giving everybody an opportunity for a basic education. At the meso-level there are the problems of institutions (schools, colleges, universities, etc.) which are curricular and organizational in nature. At the micro-level there are the teaching and learning problems, the concerns of teachers and students. At each of these levels problems can be approached with recourse to educational technology. The expertise needed will differ from level to level and depend on the type of problem, e.g., choice of curricular materials or media, curriculum development, organization of higher education, etc. In solving these problems one has to draw not only upon many disciplines, such as psychology, pedagogy and sociology, but also upon theories of methodology, instruction and curriculum, media and communication, organization and systems, and sometimes the field of informatics or computer science. A combination of specialized knowledge from these disciplines, with educational technology as a problem-solving methodology, will fully cover the domain of education and training in terms of providing the capacity to tackle problems.

The educational technologist may often use educational technology in its older meanings: technical products and the process of systematic design of instruction. This approach, and its history derived from the field of audio- 
visual media, creates in the minds of many people a technical image of educational technology. From the approach of the present authors it is clear that technology is not the same as technique. However, this technical image is not rapidly diminishing, one possible reason being that educational technology does not start from the primacy of the teacher. The role of the teacher will always be analyzed in relation to the educational setting as a whole. In this analysis there is a need to pay attention to alternative solutions in which new technological media, like computers and interactive video,-are used and are reinforcing the technical image of educational technology. This technical image is convincing some people that educational technologists should in fact be educational technocrats. After the preceding discussion we should be able to say that educational technology is nothing more or less than a methodology for solving educational problems. A large number of its practitioners have adopted this methodology, but there remain many more who are still wedded to the older concepts of the field.

\section{Educational Problems Which Could Be Addressed by Educational Technology}

One basic premise in regard to the use of educational technology is that it ought to be used in response to appropriate problems. In the past, some of the less successful uses of educational technology occurred when it was offered as a solution to a problem which had not been clearly defined. In the early days media (and to some extent computers today) were viewed as solutions looking for a problem rather than the other way round. The mystique which surrounds the new technologies causes enthusiasts to try to apply them in almost any setting without, however, raising the 'right' questions. It is far better to define and describe the problems facing a country, an organization or an individual and then consider alternative solutions which may involve technology. Unless this view is held by technology's leaders and implementers, most technological innovations are doomed to failure. There is much to recommend Shoemaker's concept of appropriate technology (1973):

One can also call it self-help technology, or democratic or people's technology a technology to which everybody can gain admittance... Although we are in possession of all requisite knowledge, it still requires a systematic, creative effort to bring this technology into active existence and make it generally visible and available. (p. 154)

What are some of the most critical problems in the educational sector? The problems differ depending upon the level of development attained. In the 
developing nations of the world, increasing numbers of children are seeking education. More and more of these students are seeking higher levels of education and training but are being thwarted by other realities. There is a shortage of qualified teachers in most countries of the world and many teachers are not fully trained. In many parts of the world, classrooms tend to be dull places where students are putting in time without developing an appetite for learning. These problems, coupled with insufficient funds for education, inevitably lead to poor student performance. The inadequacy of funding also limits the resources available to the teacher and the learner: there are insufficient numbers of textbooks, blackboards are poor, and no media other than the teacher are present. Such a bleak picture often discourages educators and government of ficials from trying to overcome the problems which exist. In the more developed nations, the problems relate to the quality of education, the societal concerns which can be dealt with in the schools, the organizational implications for multi-cultural education, and the cost-effectiveness of the investment made in education. Educational technology, it can be said, offers potential solutions to some of the most pressing problems in all areas of the world.

\section{Proposals to Alleviate the Problems}

Over the past fifty years many projects have been established by international agencies and various bilateral agreements have been made between nations in an attempt to use the mass media to resolve some of the educational problems facing developing countries. The emphasis seems to be on providing instruction on a large scale, usually through radio or television, to students who could not attend local schools. Schramm (1977) reports on most of these programmes and concludes:

Students learn from any medium, in school or out, whether they intend to or not, whether it is intended or not that they should learn ... providing that the content of the medium leads them to pay attention to it. (p. 267)

While it appeared that the media were being deployed to solve some of the critical educational problems facing a country, they were in many instances being seen as contemporary delivery systems which would help to modernize a developing nation. In the more highly developed countries, media and technology have been used as a showpiece by local schools eager to impress upon parents and community leaders that the school was on the cutting edge of the technological revolution sweeping through other sectors of society. The presence of hardware seemed to convince people inside and outside the 
schools that modern devices were being used. However, there is little data available on how these devices were used and what the results were. Hard. ware (and random software) did not appear to bring about the changes that were originally envisaged.

\section{Assumptions about the Use of Instructional Technology}

In advancing the technologies of radio, television, film, and other more traditional audiovisual media, advocates made certain assumptions. Some of these assumptions are logical and reasonable; others need to be questioned and clarified. By definition, a medium is a vehicle through which something is accomplished or conveyed. Thus, a teacher is a medium. When an instructional medium is used, it acts as a means of performing one or more instructional functions of a teacher. Perceptions that teachers are being 'replaced' by a medium seemed to override the value of the surrogate. A related assumption was that logical or reasonable justification for the use of media and technology would bring about easy acceptance by teachers, principals, and parents. It was thought that each of these groups would value educational technology.

The assumptions that economies of scale would eventually reduce costs pervaded almost every project in which media and technology were used. After the initial installation, development of materials, and training of teachers (the argument went) costs could be amortized over time for an actual net saving of educational expenses.

A final assumption was that educational problems, especially in teaching and learning, could be solved in ways similar to other sectors of society where technology had intervened to help find solutions to problems, create better lifestyles, and deliver services in an efficient and effective manner. If problems of transportation, food production and family planning could be solved by new technologies, the argument in support of educational technology seemed to be a logical one. There appeared to be a role for technology in instructional improvement, but that role was never clearly stated.

\section{What Has Happened?}

Some projects have succeeded and continue today. One of the most notable is the Open University in the United Kingdom, but there are others in China, Japan, the Federal Republic of Germany, the Netherlands, Thailand, and Pakistan, to mention but a few. Some aspects of other projects succeeded and vestiges of them remain. TV College in Chicago is still operating after 
more than thirty years but in a more limited way and for a different clientele. Other projects succeeded until the money ran out; that is, they accomplished what they set out to do and, as long as there was financial support from a donor agency, the programmes continued. The Satellite Instructional Television Experiment (SITE) in India was implemented for a specified period of time, but no continued support was forthcoming and no attempt was made to revive it, despite the fact that the data indicate that SITE achieved most of its objectives. Lastly, many other projects simply failed.

Today there appears to be less hostility toward media and technology than in earlier times, especially in the more developed areas of the world. There is an acceptance of the tools and products of our time as legitimate resources for the classroom. However, media and technology still seem to be used more as adjunct materials than as an integral part of the teaching/ learning process. They remain as audiovisual aids rather than as fundamental substantive resources for learning. They are used more for instruction than for learning and they help the teacher more than the learner. This may be because teachers are more apt to use media and technology when they can maintain control of classroom events, and do not have to make major changes in the routine of the classroom. It may also reflect the generally acknowledged poor quality of instructional materials and inadequate supplies of equipment and materials.

\section{Where Are the Successes?}

Some problems are so obvious that the solutions do not seem to be particularly inventive. In Australia, for example, radio has been used for more than fifty years to reach students in the outback. (Supplementary materials sometimes have to be dropped by aeroplane.) An insufficient number of trained teachers, especially in mathematics, led to the use of educational radio in Mexico, El Salvador, and Nicaragua. These radio lessons provide comprehensive instructional units especially in remote areas of these countries. In an attempt to prepare youngsters for primary school, Sesame Street was produced and shown in the United States and has been translated into several languages in other countries; it is not uncommon to see 'Big Bird' in many countries of the world. Microteaching, which began as a procedure for improving the training of teachers at Stanford University, has become a standard activity for teacher education around the world, permitting a teacher trainee to teach a small group of students as the lesson is being videotaped for later analysis. Audiotutorial instruction, which began as an attempt to individualize instruction for university-level botany classes, has gradually spread to other colleges and universities throughout North America. As a 
result, the number of lecture classes has been reduced and students spend more time in a laboratory carrel where the instructor's lecture is available on tape and the materials for experiments are nearby. With this form of instruction, students proceed at their own pace and their performance is usually better than that of students who attend traditionally organized classes and laboratories.

Educational technology, in its process sense, has been discovered by business, industry, the military, and health professions. When life or death matters are paramount, training programmes designed by educational technologists become very important. It should be noted that the emphasis is on training, not on education, which is broader and more general in its goals. Training programmes use the concepts and principles of educational technology to ensure the optimum performance of employees. Many of the same principles are used in education, but they are not usually as pervasive.

One very successful application of educational technology is the use of low-cost learning systems in Indonesia, Liberia, the Philippines, and Thailand. These programmes are designed for maximum student involvement, peer tutoring, and the use of simple print and audio media all organized in a systematic way in order to ensure that learning takes place (Nichols, 1982).

\section{What about the Unfulfilled Promises?}

An understanding of what makes a programme 'successful' or 'unsuccessful' can be acquired by examining the common elements which would appear to be inherent in successful projects, and those elements which would appear to be lacking in less successful programmes. What follows is a brief list of some of the reasons why some projects did not fulfill their expectations.

Goals were confused. People participating in the project did not know why educational technology was being used. They tended to think of it as a means rather than as a systematic approach to instructional development. The hidden objective was to prove the value of a specific medium or technique. Sometimes goals were set not by the users themselves but by organizations which were 'on the outside'. Ambiguity of goals leads to diffuse activities by personnel who lack the guidance of having specific goals in mind.

Emphasis on the medium. Greater importance seemed to be attached to the equipment used than to the design of the programme or accompanying materials. In these cases, a new medium was being tried out for its own sake, 
the problems to be solved taking second place to the actual use of the equipment. Instructional television in American Samoa (Schramm, 1977) was installed to provide more and better education but the emphasis was on television rather than on learning. With each new medium the advocates seemed to follow the same pattern, i.e., prove its value in comparison with traditional approaches.

Research and development in both major streams of the field have enlarged our knowledge and understanding of the possibilities of media and the instrumentation of teaching and learning processes, as well as the use of systematic design and development of instruction, curricula and courseware.

Ultimately, the influence of both developments on educational practice appears to be very limited. Most of the research conducted on the effectiveness of different modes of presentation has not yielded unequivocal results: a 'no significant difference' was almost always reported. However, when significant results were reported, there was insufficient consistency to be able to draw meaningful conclusions (see e.g., Dubin and Taveggia, 1968; Chadwick, 1979; Schramm, 1977). The early product and process approach of educational technology usually referred to physical aspects of the educational process: new aids, new media of presentation, new learning programmes, etc. The technology, i.e., the products and/or the process, was the focus of attention, but the very structure and organization of the educational processes were never part of the discussion.

Resistance to change. There are people who for various reasons simply do not want change and who are wont to scuttle the work of agents of change and innovators. The application of technology to the teaching/learning process posed a special threat for such people because, when its use was optimized, it replaced in many cases the traditional information-giving function ascribed to the teacher. Moreover, in schools where factors affecting change (commitment to change, availability of resources, etc.) are not taken into consideration, resistance to technology seems to escalate.

Lack of support systems. Basic ideas may be sound and initial resources may be provided, but without a management support system, including logistics on a day-to-day basis, project objectives become difficult to achieve. Sometimes social support systems are also lacking, and individuals trying to adopt an innovation may feel alone and without help. More sophisticated equipment often requires continual looking after, usually by technical and management personnel. If a computer or videotape recorder does not operate, provision for replacement and repair needs to be made. Support services should make it easier to use the hardware - sometimes the lack of such 
services is an impediment to its use. The new user also needs peers who are themselves trying out a new procedure and who can therefore help one another to carry through a programme. Without this type of encouragement, volunteers for innovation are not very forthcoming.

Lack of skills. Some people who are designated to use new technologies do not receive adequate training or, at worst, do not receive any training whatsoever. Opportunities to practise using the new technology must be found in the individual's own time and there is therefore little incentive to become skilled. Under such circumstances it is reasonable to expect a lack of enthusiasm and an unwillingness to risk failure.

Expense. In some cases project implementers are not aware of the expenses that will accrue during the course of operation of the project. If people have not been trained or if all the equipment has not arrived by the time the funds run out, the project is likely to fail. If new money is allocated and documented results are not available some time during the first year of operation, it is likely that financial support for the project will be cut. Sometimes alternative uses for the money become more attractive than the experiment, for example purchasing new textbooks seems to be a far better use of scarce resources than purchasing a microcomputer or videodisc unit.

Lack of quality software. After costly and visible equipment is installed, many project participants realize that they must create the 'software' to use with the hardware. If software is imported, it may be culturally inappropriate. If it is produced locally, people have to be trained in the process of instructional design. Rarely is there any type of educational technology project that has sufficient amounts of quality software, probably the most important element of the total delivery system. In addition, the general inflexibility of most software requires high fidelity between its designated pattern of use and its actual implementation. Without the opportunity for local adaptation, users have little 'ownership' in the use of software that they cannot adapt for their own purposes.

Lack of system focus. Some projects are concerned with only one (or a limited number of) aspects of the problem rather than the totality. They tend to focus on one important objective and neglect the rest. All too often, cause and effect mentality, especially in different cultures, brings about incorrect perceptions of people, procedures, and processes. Attention is given to only a few aspects of a programme and not to the entire operation. Where vision is limited, it is unlikely that systems which require substantial changes can be implemented. When a user does not perceive a new procedure as one con- 
tributory element of a larger structure, it is likely to fail or to have its effectiveness reduced.

\section{What Are the Threads Which Run through Successful Programmes?}

When successful problem-oriented, technology-based programmes are analyzed, there appear to be a series of strands which run through most of them. Some of the most frequently found themes are given below:

- Successful programmes using technology meet such critical educational needs as a shortage of teachers, insufficient space for classrooms, or escalating costs.

- Such programmes are oriented towards the individual learner rather than toward the teacher. When instruction is designed on the basis of what the learner must be able to do, new software based on the principles of instructional design often emerges. If these principles have been followed, the problem rests with the materials rather than the teacher if the student does not learn.

- Successful programmes are cost-effective. The best examples come from the use of radio in developing countries. With increasing sophistication in accounting for the outputs of educational programmes, measures of effectiveness are emerging along with measures of efficiency.

- Delivery systems are relatively simple and available. Less exotic media such as audio cassettes and programmed learning courses are having remarkable success in a large number of developing countries. In many cases where simple media are used, the emphasis is not on the medium, but on the systematic approach to instruction.

- Closely related to the use of simple delivery systems is the emphasis on the design of the system. New, research-based (Gagné and Briggs, 1979) procedures are being recognized as important elements in the process of teaching and learning.

- Projects and programmes which succeed are more often involved in training than in education. Since the purposes of training are more often directed toward measurable skill competencies, it is logical that such efforts would yield specific positive results. The wider range and amorphous quality of education makes it difficult to assess whether goals have been attained, for these goals are usually of a more general nature. 


\section{What Have We Learned?}

The results of our analysis have produced a number of general guidelines which, if followed, would be likely to bring about the successful implementation of educational programmes. These guidelines should continue to be tested and altered as necessary. They may be followed using either the product or process approach to educational technology, but they would work best at the problem-solving level where all aspects which impinge upon the teaching/learning process are factored into a comprehensive design.

1. Begin with a problem to be solved, not with a medium or instrument to be used. Selection of the hardware and software should grow out of specific needs which have already been identified.

In its best sense, educational technology uses a systematic approach to problem solving in teaching/learning contexts. It serves users most effectively when it addresses the total problem rather than one part of it. Open universities begin by exploring the need to provide tertiary education to large numbers of secondary school graduates and adults who do not have access to a college or university setting.

2. Analyze the context in which the teaching and learning will take place. Consider all of the elements which will influence the process. (Some would suggest carrying out a needs assessment as part of the analysis of the contextual environment.) With these data in hand, develop a comprehensive plan for the design, installation, and maintenance of any new practice. Such a plan would involve potential users in the process and would provide for training along the way. Organizing for the management of a project is as important as the substance of the effort.

3. Let the design of the materials reflect the philosophy of the programme and the strategies which will be used in implementation. These elements (materials, beliefs, and strategies) work together - attention to one without concern for the others will eventually lead to a mismatch of materials and learners.

4. Focus on the individual learner - build in active participation - provide feedback. This shift from teacher to learner is a major change in the teaching/learning process. It begins with a series of statements about student outcomes, i.e., what students should be able to do at certain points in the process. What the teacher does is to arrange the right conditions for learning to take place; these conditions include facilities, materials, time, grouping and opportunities for practice. 
5. Select simple, available media. These should be integrated into the design and not be considered as optional or ancillary. Research shows that media can teach content at least as effectively as traditional instruction. Moreover, well-designed media can help learners to gain more than from traditional instruction.

6. Determine the role of the teacher. If media are to carry some of the content, the teacher's role must change. The teacher will be less of an information-giver and more of a learning facilitator. Fewer professional teachers may be required if roles are modified and teacher aides or assistants are used alongside professional teachers. In no way should the teacher be denigrated; he/she is still the primary resource person but now serves as more of a manager than as a fountain of knowledge. The more a teacher participates in the planning of instructional delivery, the greater the fidelity to an agreed-upon implementation design.

7. Set up support systems to assist the teachers and students. Support systems might include logistic help, counselling, resource people, and technical assistance. They are as important as all other elements of the system. Without support, the instructional delivery will not 'work' at an optimum level. Again, as with the teacher, roles must be defined and criteria for using the support systems should be developed.

These guidelines have been derived from actual practice and stem from current thinking about educational technology as a problem-solving process for teaching and learning.

\section{What Is Past Is Prologue ... or Is It?}

Some historians believe that events are cyclical over time; some psychologists believe that the best indicator of future behaviour is past behaviour; some philosophers say that we learn from our mistakes. All of these viewpoints seem to describe the activities of educational technology over the past fifty years.

What might be viewed as a failure to install many of the instruments and artefacts of educational technology might in fact be a sign of maturity, a sign that advocates have learned what the proper role of educational technology really is. In a world where the products of a technological age are visible in many sectors of society, it is reasonable to think that these fruits of our labours are potentially useful in the educational sector as well. We have learned that we must buy products that have been originally designed 
for other purposes and adapt them to educational settings. We thought that mere acquisition was sufficient to begin using these new technological delights, but soon learned that there were no quick and easy roads to success. We have learned that hardware was insufficient to achieve educational goals. We have learned that the goals of education were quite different from those of other sectors of society.

To say that we have failed or learned very little is to miss the point. We have learned about education, teaching, and learning. We have learned that there is no easy road to educational success. We have learned that media which entertain do not necessarily teach. We have learned that there are better ways to design software. We have learned that we must deal with the whole rather than the parts. We have learned that education is not an institution that can be revolutionized easily - but that evolution can be accelerated. We have learned that educational technology is a problem-solving process, not a product.

The current innovation is information technology or, more specifically, the computer. What will happen in the future? Will the mistakes of the past be repeated? Will the next fifty-year analysis be similar to this one? The potential for failure is still there. We have a visible piece of hardware with software that has been developed largely for business, industry, the military, or government purposes. Worldwide problems in education still exist, and the urgent calls for a 'quick fix' are creating pressure to embrace new technologies. The basic structures of education are the same, and most teaching continues to be offered in classrooms with groups of learners being taught by an individual teacher. This age-old practice is probably the single most effective deterrent to improvements in learning. Until educators realize that new times demand new configurations for teaching and learning, we will continue to find pockets of innovation which may or may not make much difference to the advancement of learning. Teachers have a role to play in this new configuration; so does technology. The past fifty years have taught us how to bring about changes that will improve learning and make it more exciting. Critical problems of numbers and space, especially in developing nations, can be addressed by new and systematic configurations of learning environments where teachers, technology, and techniques make their optimum contribution to the process of teaching and learning. To do less is to deny the advances of the past fifty years. To do more is to launch education on a path towards the twenty-first century. 


\section{References}

Association for Educational Communications and Technology. The Definition of Educational Technology. Washington, D.C.: AECT, 1977.

Botkin, J.W., Elmandjra, M. and Mailitza, M. No Limits to Learning: Bridging the Human Gap: The Club of Rome Report. Oxford: Pergamon Press, 1979.

Chadwick, C.B. 'Why Educational Technology is Failing (and What Should Be Done to Create Success)'. Educational Technology. January (1979), pp. 7-19.

Cuban, L. Teachers and Machines: The Classroom Use of Technology. New York: Teachers College Press, 1985.

Davies, I.K. 'Educational Technology: Archetypes, Paradigms and Models'. In Hartley, J. and Davies, I.K. (eds.). Contributing to Educational Technology, Vol. 2. London: Kogan Page, 1978.

Diamond, R. 'Instructional Design: Systems Approach'. In Husén, T. and Postlethwaite, T.N. (eds.). The International Encyclopedia of Education. Oxford: Pergamon Press, 1985, pp. 2258-2563.

Dick, W. and Carey, L. The Systematic Design of Instruction. Glenview, IL: Scott, Foresman and Co., 1978.

Dubin, R. and Taveggia, T.C. The Teaching Learning Paradox. Eugene, OR: University of Oregon Press, 1968.

Ely, D.P. 'The Definition of Educational Technology: An Emerging Stability'. Educational Considerations. X (1983), No. 2 (Spring), pp. 2-4.

Ely, D.P. 'Education and Training: Two Paths or One?'. Programmed Learning \& Educational Technology. 22 (1985), No. 1, pp. 75-77.

Faure, E. et al. Learning to Be: The World of Education Today and Tomorrow. Paris: Unesco, 1982.

Fullan, M. 'Curriculum Implementation'. In Husén, T. and Postlethwaite, T.N. (eds.). The International Encyclopedia of Education. Oxford: Pergamon Press, 1985, pp. 1208-1215.

Gagné, R. and Briggs, L. Principles of Instructional Design. New York: Holt, Rinehart and Winston, 1977.

Gerlach, V.S. and Ely, D.P. Teaching and Media: A Systematic Approach. Englewood Cliffs, N.J.: Prentice Hall, Inc., 1980.

Heinich, R. 'The Proper Study of Instructional Technology'. Educational Communications and Technology Journal. 32 (1984), No. 2, pp. 67-87.

Lumsdaine, A.A. 'Educational Technology, Programmed Learning, and Instructional Science'. In Hilgard, E.R. (ed.). Theories of Learning and Instruction. Chicago: University of Chicago Press, 1984, pp. 371-401.

Nichols, D.G. 'Low-Cost Learning Systems: The General Concept and Some Specific Examples'. NSPI Journal. September 1982, pp. 4-8.

Plomp, T. Enige verkenningen. Enschede: T.H. Twente, 1982 (in Dutch). 
Romiszowski, A.J. Designing Instructional Systems. London: Kogan Page, 1981. Saettler, P. A History of Instructional Technology. New York: McGraw Hill, 1968. Schramm, W. Big Media, Little Media. Beverly Hills: Sage Publications, 1977. Shoemaker, E.F. Small is Beautiful. London: Blond \& Briggs Ltd., 1973.

Stakenas, R.G. and Kaufman, R. Technology in Education: Its Human Potential. Bloomington: Phi Delta Kappan, 1981.

Tickton, S.G. To Improve Learning: An Evaluation of Instructional Technology. New York: Bowker, 1970. 